\title{
Chronic postsurgical pain: current evidence for prevention and management
}

\author{
${ }^{1}$ Department of Anaesthesiology and Critical Care, B. P. Koirala Institute of Health Sciences, Dharan, Nepal, \\ ${ }^{2}$ Department of Anesthesiology, Siriraj Hospital, Mahidol University, Bangkok, Thailand
}

Parineeta Thapa ${ }^{1}$ and Pramote Euasobhon ${ }^{2}$

\begin{abstract}
Chronic postsurgical pain (CPSP) is an unwanted adverse event in any operation. It leads to functional limitations and psychological trauma for patients, and leaves the operative team with feelings of failure and humiliation. Therefore, it is crucial that preventive strategies for CPSP are considered in high-risk operations. Various techniques have been implemented to reduce the risk with variable success. Identifying the risk factors for each patient and applying a timely preventive strategy may help patients avoid the distress of chronic pain. The preventive strategies include modification of the surgical technique, good pain control throughout the perioperative period, and preoperative psychological intervention focusing on the psychosocial and cognitive risk factors. Appropriate management of CPSP patients is also necessary to reduce their suffering. CPSP usually has a neuropathic pain component; therefore, the current recommendations are based on data on chronic neuropathic pain. Hence, voltage-dependent calcium channel antagonists, antidepressants, topical lidocaine and topical capsaicin are the main pharmacological treatments. Paracetamol, NSAIDs and weak opioids can be used according to symptom severity, but strong opioids should be used with great caution and are not recommended. Other drugs that may be helpful are ketamine, clonidine, and intravenous lidocaine infusion. For patients with failed pharmacological treatment, consideration should be given to pain interventions; examples include transcutaneous electrical nerve stimulation, botulinum toxin injections, pulsed radiofrequency, nerve blocks, nerve ablation, neuromodulation and surgical management. Physical therapy, cognitive behavioral therapy and lifestyle modifications are also useful for relieving the pain and distress experienced by CPSP patients. (Korean J Pain 2018; 31: 155-73)
\end{abstract}

Key Words: Chronic pain; Drug therapy; Incidence; Intractable pain; Neuropathic pain; Operative surgical procedure; Pain management; Physical therapy modalities; Postoperative pain; Prevention; Therapeutic methods.

\section{INTRODUCTION}

Pain lasting longer than the normal healing process after surgery is an unwanted adverse event in any operation.
Chronic postsurgical pain (CPSP) was first defined in 1999 by Macrae and Davies [1], and later expanded by Macrae [2] in 2001, as "pain that develops after surgical intervention and lasts at least 2 months; other causes of pain

Received January 17, 2018. Revised February 23, 2018. Accepted March 15, 2018.

Correspondence to: Pramote Euasobhon

Department of Anesthesiology, Siriraj Hospital, Mahidol University, Bangkok 10700, Thailand

Tel: +66-2-419-7842, Fax: +66-2-411-3713, E-mail: pramoteo@hotmail.com

(a) This is an open-access article distributed under the terms of the Creative Commons Attribution Non-Commercial License (http:// creativecommons.org/licenses/by-nc/4.0/), which permits unrestricted non-commercial use, distribution, and reproduction in any medium, provided the original work is properly cited.

Copyright (c) The Korean Pain Society, 2018 
have to be excluded, in particular, pain from a condition preceding the surgery". An updated definition of CPSP, or persistent postsurgical pain (PPSP), was later proposed by Werner and Kongsgaard in 2014 [3]. The proposed definition was "pain persisting at least three months after surgery, that was not present before surgery, or that had different characteristics or increased intensity from preoperative pain, localized to the surgical site or a referred area, and other possible causes of the pain were excluded (e.g., cancer recurrence, infection)". CPSP can represent a severe nuisance to patients, leading to functional limitation and psychological trauma, as well as a problem for the operative team in the form of feelings of frustration and disappointment.

We sought to explore the acute to chronic pain transition in postsurgical patients. To identify the incidence, risk factors, preventive and treatment strategies for CPSP, we searched the Ovid MEDLINE, EMBASE, and Cochrane databases between 1990 and 2017. The search utilized combinations of the following keywords: chronic postsurgical pain, persistent postsurgical pain, pain after surgery, chronic postoperative pain, incidence, risk factors, prevention, phantom limb pain, failed back surgery, post-laminectomy pain, post-thoracotomy pain and post-mastectomy pain. We limited our search to humans and English. Relevant articles were identified by the authors from the abstracts and the bibliographies.

\section{MAIN BODY}

\section{Incidence}

A study by Fletcher et al. of surgical patients in Europe demonstrated that $11.8 \%$ of patients have moderate to severe pain, while $2.2 \%$ have severe pain (NRS $\geq 6$ ), at 12 months after surgery [4]. Persistent pain can occur following various operations, ranging from simple and common ones (to illustrate, herniorrhaphy, caesarean section or dental extraction) to complicated surgeries (such as thoracotomy, radical mastectomy or hysterectomy).

The reported incidence of CPSP varies for different surgical procedures and in different studies, ranging from a low of $5 \%$ to a high of $85 \%$. For example, studies have reported incidences ranging from 50\%-85\% following limb amputation, $11 \%-57 \%$ following mastectomy, 30\%-55\% after cardiac surgery, 5\%-65\% after thoracotomy, and
$5 \%-63 \%$ following hernia repair [5]. One reason for this variability is the difference in the time reference considered by each researcher for labeling pain as CPSP (varying from 2 months to 1 year postoperatively).

Also, the amount of injury to the tissues or nerves and the degree of inflammation differ by operation type and procedure for the same surgery. For instance, according to the study by Fletcher, there is a reduced incidence of moderate to severe CPSP with laparoscopic cholecystectomy (8.8\%) than with open cholecystectomy (28\%). Fletcher's study also found that orthopedic surgery is associated with an almost three-fold increased risk of moderate to severe CPSP, compared with all other procedures, at 12 months [4]. The sensitivity of patients to pain is also variable.

\section{Risk factors}

Besides the type and approach of surgery, various other risk factors have been attributed to CPSP. Some of them are patient factors (including female gender, being a young adult, genetic predisposition, and psychosocial factors), preexisting patient conditions (for example, pain present preoperatively, and any preexisting painful conditions in other parts of the body), and perioperative factors (for instance, duration and type of surgery, extent of nerve damage intraoperatively, and severity and duration of acute postoperative pain).

A recent study has also demonstrated that the severity of pain in CPSP is correlated with the mRNA expression of the signal transduction genes, representing the genetic influence on CPSP [6]. The most consistent feature associated with the occurrence of CPSP is the duration of the severe acute postoperative pain. Acute pain can lead to central sensitization, which reduces the mechanical threshold and exaggerates the response to noxious stimuli. The patient can thus present with both hyperalgesia and allodynia [7,8].

\section{Prevention}

Currently, there is no definitive way to prevent the occurrence of CPSP. Various techniques have been tried, by anesthesiologists and surgeons alike, to reduce the risks, but with variable success. Identifying the risk factors in each patient and applying a timely preventive strategy may help 
patients to avoid the distress of chronic pain.

\section{1) Modification of surgical technique}

One of the risk factors for CPSP is the extent of tissue damage during surgery and injury to the nerves during dissection or retraction. Nerves are at continuous risk of contusion, stretching, division or entrapment from insults like surgical retraction, diathermy, or compression with bones. Alfieri in his prospective study showed that a lack of identification of nerves (the ilioinguinal, iliohypogastric and genitofemoral nerves) is significantly correlated to the presence of chronic pain following herniorrhaphy, with the risk of the development of inguinal pain climbing with the number of nerves that are not detected [9].

\section{(1) Minimally invasive surgery}

Since there is less tissue trauma in minimally invasive surgery, less chronic pain is expected than in open procedures. However, results have not always been positive. A Cochrane study involving 41 published reports of eligible trials involving 7161 participants found that there was less persistent pain and numbness following laparoscopic repair [10]. Still, another meta-analysis by Karthikesalingam et al. did not find any significant difference in the incidence of chronic pain following the laparoscopic or open-mesh repair of a recurrent inguinal hernia.

Nevertheless, only three trials were included in that study, and the meta-analysis defined CPSP as pain persisting for at least one year (instead of the generally more appropriate period of 3 months) after surgery [11]. Furthermore, a prospective randomized study on the incidence of chronic groin pain (CGP) and the impact on the quality of life 10 years after laparoscopic (transabdominal preperitoneal-TAPP) versus open (mesh) repair for bilateral and recurrent inguinal hernias found that laparoscopic repair had a higher incidence of CGP (15\%) compared to the open group (8\%). The severity of pain was, however, lower following the laparoscopic repair [12]. Some studies have also shown that a laparoscopic hysterectomy is superior to a vaginal hysterectomy in terms of acute postoperative pain, analgesic needs, and hospital stay [13], but the type of hysterectomy did not affect the occurrence of chronic pain [14].

In the case of thoracotomy, many factors are related to CPSP. These include, for instance, the surgical approach [video-assisted thoracoscopic surgery (VATS) vs open thoracotomy], the type of incision for open procedures (posterolateral vs. muscle sparing vs. sternotomy vs. transverse sternothoracotomy), rib resection or retraction, the extent of intercostal nerve preservation, and the method of rib approximation after the procedure. However, VATS does not reduce the incidence of CPSP, despite there being some reduction in the incidence of acute postoperative pain compared to open thoracotomy [15].

Minimally invasive surgery is also recommended for orthopedic surgery to limit tissue damage and nerve injury [16]. Unfortunately, arthroscopic surgeries can also lead to CPSP due to injury to the nerves (to illustrate, branches of the saphenous nerve during a knee arthroscopy) as this cannot always be avoided due to the proximity of the nerves to the bones.

\section{(2) Less extensive surgery}

The resection, rather than the retraction, of a rib leads to reduced trauma to the intercostal nerve and thus decreases the incidence of CPSP. CPSP is also less following sternotomy than that following thoracotomy [15].

However, there are various other sources of pain; among those are the site of an internal mammary artery dissection, stainless steel suture, surgical scar, tissue destruction from surgery and inflammation, rib fracture, and intercostal nerve trauma. As well, the sources of chronic pain following a coronary artery bypass graft can be the upper or lower limb from where the vascular graft was harvested, or the site of the central venous catheter insertion [17].

During inguinal hernia repair, indiscriminate division of the subcutaneous tissue; excessive dissection of the ilioinguinal nerve; damage of the neural structures during stretching, cutting, suturing or cauterization; overtightening of the inguinal ring; removal of the cremaster muscle fibers; and suturing of the edge of the internal oblique muscle have all been found to be associated with an increased occurrence of CPSP [18]. Another factor found to increase CPSP is the closure of the parietal peritoneum following an abdominal hysterectomy rather than the closure of the fascia, leaving the parietal peritoneum unsutured [13].

Post-mastectomy pain syndrome (PMPS), which pres- 
ents with pain typically localized to the axilla, the medial upper arm, and/or the anterior chest wall on the affected side, occurs most probably due to damage to the intercostobrachial nerve, which can occur during axillary node dissection. Consequently, the risk of damage to the intercostobrachial nerve and the development of PMPS is as likely with a lumpectomy with an axillary dissection as with mastectomy. A sentinel lymph node biopsy during a lumpectomy or mastectomy can help prevent unnecessary $\mathrm{ax}^{-}$ illary dissection, thus reducing the occurrence of CPSP [19]. Other sources of neuropathic pain following breast cancer surgery are damage to the medial and lateral pectoral, long thoracic, or thoracodorsal nerves.

A further surgical factor consistently related to CPSP is the duration of surgery. Operations lasting longer than three hours are found to be associated with an increased CPSP [20,21].

Despite there being insufficient evidence to recommend a definite surgical technique to eliminate the possibility of CPSP, surgeons can minimize the risk of CPSP by choosing a minimally invasive surgical technique, employing careful dissection to avoid injury to nerves, avoiding extensive surgery whenever possible, and/or minimizing the duration of surgery if possible.

\section{2) Treatment of preoperative pain}

The presence of pain before surgery and the severity and duration of acute postoperative pain are predictors of CPSP. Neuroplasticity (spinal sensitization) following trauma may transform an acute pain to chronic pain if not treated in a timely manner. This can be prevented by aggressive treatment of acute pain [18]. Therefore, good perioperative pain management is thought to prevent the occurrence of CPSP. In a study by Karanikolas et al. of 65 patients who underwent lower limb amputation, the incidence of phantom limb pain after 6 months decreased significantly more following the use of an optimized perioperative epidural analgesia, or if an intravenous $\mathrm{pa}^{-}$ tient-controlled analgesia was started 48 hours preoperatively and continued for 48 hours postoperatively, compared with patients who received conventional analgesia and genral anesthesia [22].

\section{3) Modification of anesthetic technique}

Perioperative management, especially the analgesic technique adopted, has a significant effect on the prevention of CPSP. Randomized controlled trials have demonstrated a positive effect of regional anesthesia on the prevention of CPSP following laparotomy, caesarean section, cardiac surgery, breast surgery, etc. Regional analgesia techniques, for instance, epidural anesthesia, wound infiltration and intercostal nerve blocks, have been studied [23]. Unfortunately, the results are not as consistent for the prevention of chronic pain as they are for the prevention of acute pain [24].

A Cochrane review has found epidural anesthesia and paravertebral blocks significantly decrease the incidence of CPSP at 6 months following thoracotomy and breast surgery, respectively. The review, however, did not comment on the benefits for other surgeries because of the lack of studies and the small sample size [25]. Another non-randomized study by Borghi et al. examined the preoperative percutaneous insertion of a peripheral nerve catheter for the postoperative infusion of local anesthetics following limb amputation. The infusion was continued for a median of 30 days. They found that the incidence of phantom limb pain at 12 months was 16\%, much less than the background incidence quoted in other studies [26,27]. Intraarticular injections of local anesthetics during arthroplasty and other joint surgeries can be effective in achieving better postoperative pain control. Wound infiltration with local anesthetics following removal of an iliac crest bone graft led to lowered iliac bone chronic pain over 4 years of follow-up [18]. Still, the result with wound infiltration is not consistent with the prevention of CPSP [28].

The adoption of preventive analgesia (providing analgesia throughout the perioperative period, thereby blocking the noxious stimulus during this painful period) rather than preemptive analgesia (providing analgesia to block the noxious preoperative stimulus) has also shown benefit in preventing CPSP [21,29]. One study compared three analgesic techniques: thoracic epidural analgesia initiated preoperatively and intraoperatively (with $\mathrm{pa}-$ tient-controlled epidural analgesia provided postoperatively in both instances); and intravenous patient-controlled analgesia with morphine, started postoperatively. It was found that CPSP was significantly reduced 6 months postoperatively by using the thoracic epidural analgesia ini- 
tiated preoperatively [30]. In contrast, another study did not find a difference in the incidence of chronic phantom pain with an epidural analgesia throughout the perioperative period, compared with the use of a patient-controlled opioid analgesia throughout the perioperative period [27]. Consequently, good pain control throughout the perioperative period seems more important than the technique used to achieve the pain control.

Evidence shows that the duration of acute pain influences the development of CPSP. A one-year follow-up study showed that the sum of the postoperative visual analog scores (VAS) during the first week after a laparoscopic cholecystectomy was a better predictor of the development of CPSP than the maximum reported VAS [31]. Hence, aggressive postoperative pain management might reduce the chance of developing CPSP.

The use of multimodal analgesia during the perioperative period has been proven to be better for acute postoperative pain management. Drugs acting by various mechanisms can more effectively manage pain by modulating pain signals at various points of the pain pathway than by using a single drug.

Multimodal pain regimens might include combinations of gabapentin, NSAIDs, acetaminophen, and regional anesthesia with the conventional analgesia technique [32]. Very few studies have been done to evaluate the effects of multimodal analgesia on CPSP. Fassoulaki et al. randomized 50 patients undergoing breast cancer surgery to receive gabapentin, a eutectic mixture of local anesthetic cream and ropivacaine wound infiltration, or three placebos. They found that pain and analgesic consumption was significantly less 3 months after the surgery in the multimodal analgesia group than the control [33].

\section{4) Pharmacological treatment}

Various pharmacologic agents have been tried to prevent CPSP, with some agents showing promising results. Some of the reference studies are listed in Table 1.

\section{(1) Gabapentin and pregabalin}

Most, if not all, cases of CPSP include neuropathic pain. Since the anticonvulsants gabapentin and pregabalin are the preferred agents for neuropathic pain, they have been tried for CPSP. A systematic review and meta-analysis by
Clarke et al., which included 8 studies on gabapentin and 4 studies on pregabalin for use in the prevention of CPSP, found that 6 of the gabapentin trials showed a moderate to large reduction in the occurrence of CPSP (pooled odds ratio [OR] 0.52; 95\% confidence interval [CI], 0.27 to 0.98; $P=0.04$ ), while a large reduction was found in 2 pregabalin trials (pooled OR 0.09; 95\% CI, 0.02 to 0.79; $P$ $=0.007$ ) [29]. Nevertheless, the dosage regimen used differed in the various studies, ranging from a single preoperative dose (of 600 or $1200 \mathrm{mg}$ of gabapentin) to perioperative use (starting with 300 or 1200 mg of gabapentin preoperatively, and continuing for 8 to 10 days postoperatively).

Similarly, pregabalin (150 or $300 \mathrm{mg}$ ) was used preoperatively and then continued postoperatively - in some studies, for only 2 more doses, but in others, for up to 2 weeks. Another systematic review and meta-analysis was conducted by Mishriky et al. to assess the analgesic efficacy of perioperative pregabalin. They found that pregabalin significantly reduced the incidence of pain at 6 months (4\% vs 15\%) and 12 months (9\% vs 20\%; RR [95\% $\mathrm{CI}]=0.31\left[0.10,0.92, \mathrm{I}^{2}=15 \%\right]$ and $0.47\left[0.23,0.97, \mathrm{I}^{2}\right.$ = $0 \%$, respectively) [34].

This promising result with gabapentin and pregabalin is now considered to be due to the preventive analgesic effect provided by gabapentinoids [35]. Despite that, a recent review of 18 randomized controlled trials (RCTs) with published and unpublished studies demonstrated that pregabalin could not reduce the incidence of CPSP at 3 months with a moderate quality of evidence [36].

\section{(2) Antidepressants}

Tricyclic antidepressants and serotonin-norepinephrine reuptake inhibitors are commonly used for chronic pain patients, both due to their efficacy in reducing neuropathic pain and the common association of depression with chronic pain. Nonetheless, studies of their use in the prevention of CPSP are too heterogeneous to allow a definite conclusion to be made.

A study by Amr et al. comparing the effects of gabapentin and venlafaxine on post-mastectomy pain found that venlafaxine extended-release $(37.5 \mathrm{mg} / \mathrm{d})$ significantly reduced chronic pain at 6 months compared to gabapentin (300 mg/d); both started on the night before surgery and continued till 10 days postoperatively [37]. Wong et al. tried 


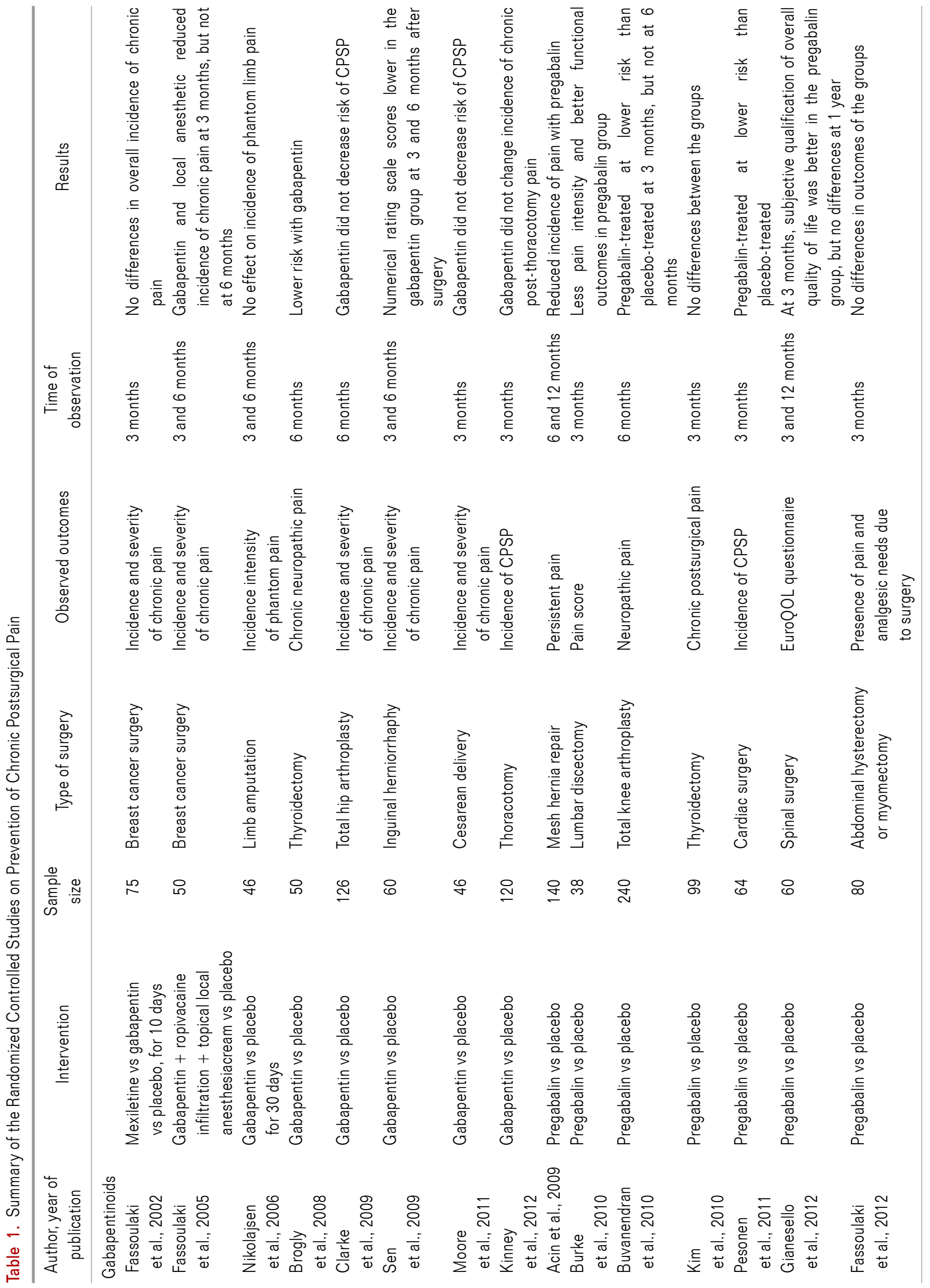




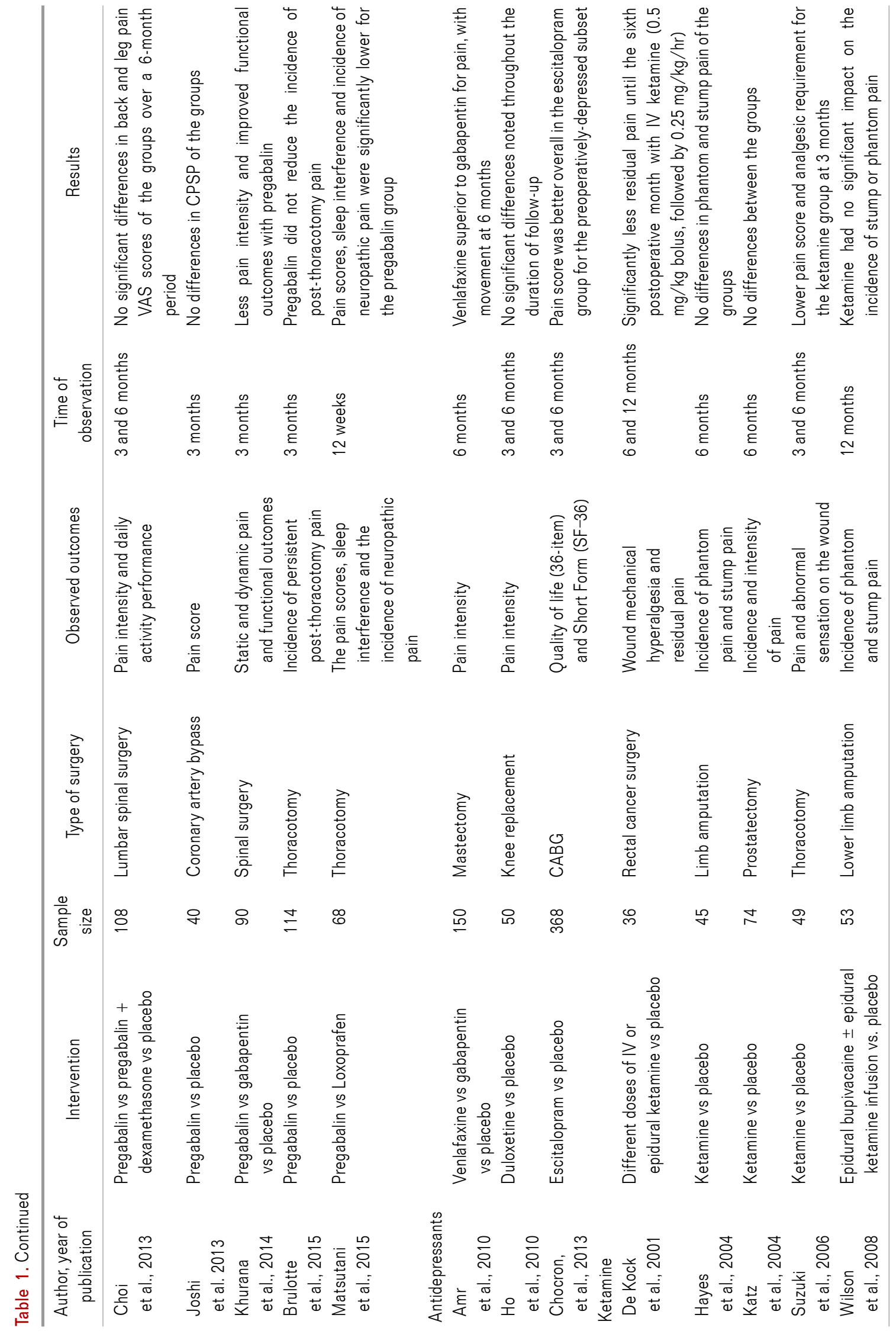




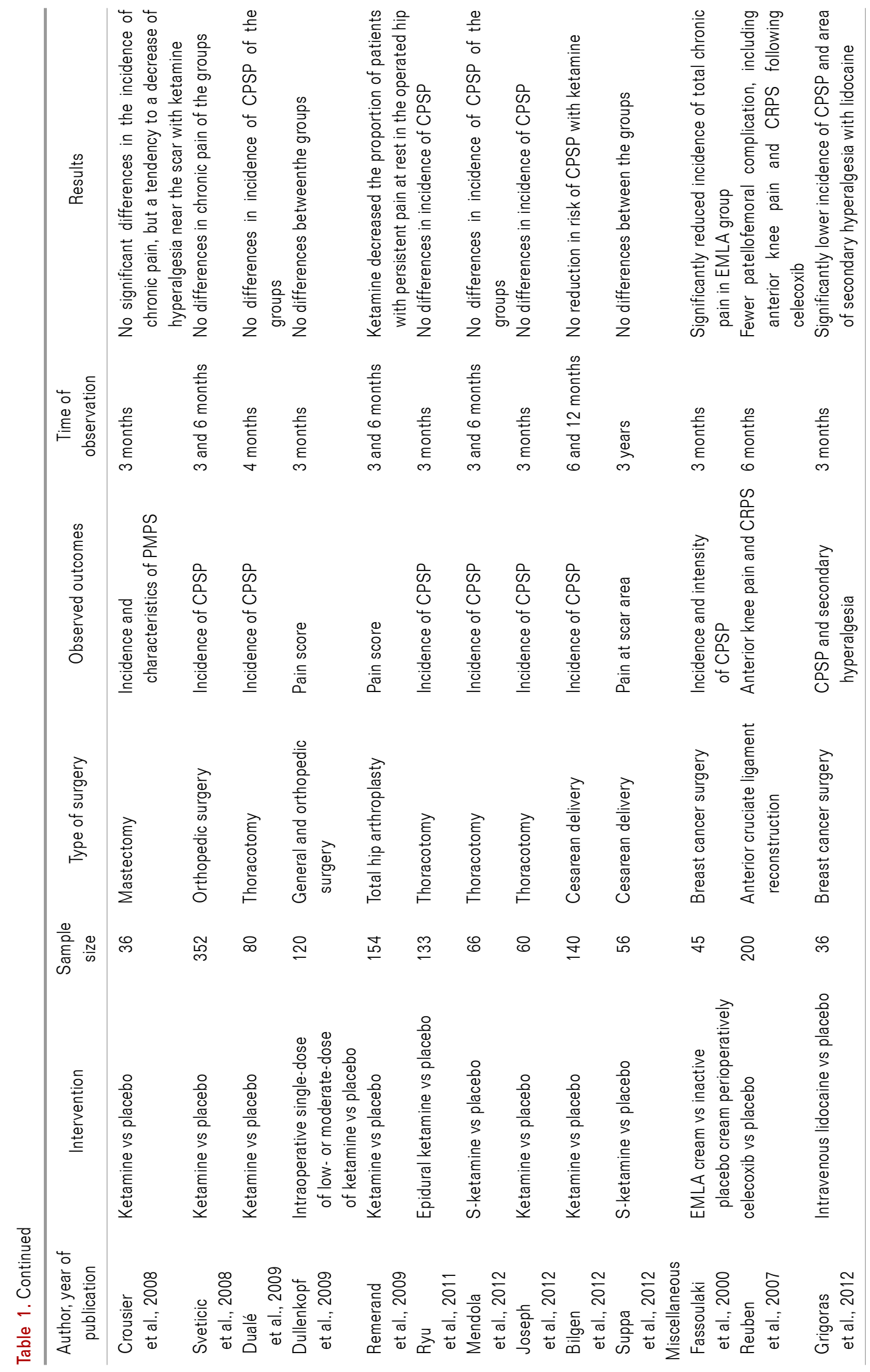


to review the use of antidepressants for the prevention of CPSP but examined only three trials, using venlafaxine, duloxetine, and escitalopram, with a positive outcome seen only with venlafaxine [38].

Overall, the limited data on the use of antidepressants presently precludes their use for the prevention of CPSP.

\section{(3) NMDA antagonists}

The benefits of the perioperative use of a subanesthetic dose of ketamine for the prevention of various types of CPSP, including phantom limb pain, has been demonstrated in different studies [39]. Significant reduction in pain for up to 6 months postoperatively has been seen with intravenous ketamine in patients undergoing colon resection [18]. A systematic review and meta-analysis was done by McNicol et al. [40] to evaluate the effectiveness of ketamine in reducing the prevalence and severity of PPSP, and to assess the safety associated with its use.

Although their meta-analysis of combined routes of ketamine use did not show any significant difference from a placebo, the analysis of the exclusively intravenous route showed a statistically significant reduction in the risk at 3 and 6 months $(P=0.01$ and $P=0.04$, respectively), with a risk reduction of $25 \%$ and $30 \%$, respectively. They recommended intravenous bolus doses in the range of $0.2-0.75 \mathrm{mg} / \mathrm{kg}$, and infusions of $2-7 \mathrm{mcg} / \mathrm{kg} / \mathrm{min}$ for the prevention of CPSP. They did not find any statistically significant difference in the incidence of side effects (hallucinations, nightmares, excessive sedation, nausea and vomiting) except for visual disturbances (in particular, nystagmus and diplopia) with the use of ketamine, as opposed to the concern of many clinicians regarding the use of ketamine.

The use of other NMDA antagonists, one example being memantine, has not yet been established, but the pain relief does not seem to persist for long enough to prevent CPSP $[21,39]$.

\section{(4) Clonidine}

Alpha-2 agonists such as clonidine are now well recognized for their acute analgesic effect and are frequently used perioperatively. A study of subarachnoid clonidine (300 $\mathrm{mg}$ ) and bupivacaine, compared with bupivacaine alone, for colon surgery found that the incidence of chronic pain af- ter 6 and 12 months was significantly less [18].

Even though there are currently few studies on the use of these agents in preventing CPSP, it has been suggested that their anti-inflammatory and anti-sensitizing effects warrants the further investigation of these drugs for the prevention of chronic pain [27].

\section{(5) Lidocaine}

Besides the use of local anesthetics for perineural injections, the use of intravenous lidocaine is increasing for the management of chronic pain, as well as perioperatively for the reduction of acute postoperative pain. Local anesthetics interrupt the sensory information to the spinal cord and thus reduce sensitization.

An intraoperative, intravenous, lidocaine infusion has been found to be effective for the prevention of CPSP after breast cancer surgery in a study conducted by Grigoras et al. Their study used a $1.5 \mathrm{mg} / \mathrm{kg}$ bolus of intravenous lidocaine before induction of general anesthesia, which was then followed by lidocaine infusion at $1.5 \mathrm{mg} / \mathrm{kg} /$ hour; the control group used an equal volume of saline. They found a significant reduction in the incidence and severity of CPSP with lidocaine at 3 months postoperatively $(P=$ 0.031) [41].

Perioperative EMLA (eutectic mixture of local anesthetic) cream has also been found to reduce the incidence of chronic pain after a mastectomy [28].

However, a Cochrane review did not find many studies to further analyze the effects of lidocaine. Consequently, more research is required before its use in the prevention of CPSP can be recommended [42].

\section{(6) NSAIDs and acetaminophen}

Though NSAIDs have a beneficial effect on acute pain, are opioid sparing, and are believed to reduce secondary hyperalgesia and central sensitization, their effects on the prevention of CPSP has not been demonstrated in any study. The use of ibuprofen for the prevention of chronic pain following hip replacement surgery or a mastectomy, and the use of parecoxib during augmentation mammoplasty, have not shown any significant reduction in the incidence of CPSP $[32,43]$. As the data presently available is very limited and restricted to only a few agents, it is not possible to draw any conclusions about the use of 
NSAIDs for CPSP.

No RCT has been conducted to show the effect of acetaminophen in preventing CPSP, though its use is now an integral part of multimodal perioperative pain management. Its role in CPSP prevention has not yet been identified.

A study by Reuben et al. of 200 patients undergoing anterior cruciate ligament surgery who received acetaminophen (1 gram) and either celecoxib or a placebo for 1-2 hours preoperatively, along with intraarticular analgesics, found that more patients in the control group developed patellofemoral complications, which included anterior knee pain and complex regional pain syndrome, among others, 6 months after the surgery [44].

\section{(7) Steroids}

Since development of chronic pain involves neuroinflammation and as steroids have an anti-inflammatory effect, steroids might be a promising agent for CPSP prevention. Although its effect on acute pain management has already been established, the data available for chronic pain is limited to date.

A Cochrane review found only 3 studies of steroids for chronic pain, too few and too heterogeneous for a meta-analysis. One of the studies found no difference in CPSP when $40 \mathrm{mg}$ of dexamethasone was given before a total hip arthroplasty, yet another study found a significant difference for the prevalence of hyperesthesia, but not pain, with a single dose of methylprednisolone (125 mg) given prior to augmentation mammoplasty. The third trial using a stress dose of intravenous hydrocortisone (a loading dose plus four days infusion) after cardiac surgery found a significant positive impact on chronic pain and chronic stress symptoms [42,45].

By contrast, a recent prospective, randomized, 1-year follow-up study of the use of $16 \mathrm{mg}$ intravenous dexamethasone after lumbar discectomy found a significantly higher pain score for the dexamethasone group, though there was no difference in the patients' ability to work, disability, or self-reported health [46].

Thus, the use of steroids for the prevention of CPSP cannot be recommended with the data currently available.

\section{(8) Opioids}

Opioids are the analgesics of choice for intraoperative and postoperative analgesia for moderate to severe pain. Since severe postoperative pain is a CPSP risk factor, opioids may help in preventing CPSP. Unfortunately, strong opioids are also associated with opioid-induced hyperalgesia.

Remifentanil, which is a short-acting, strong opioid, and a popular component of balanced anesthesia, has been found to increase CPSP when used intraoperatively. However, total intravenous anesthesia with propofol and remifentanil has been more closely associated with reduced chronic post-thoracotomy pain than inhalation anesthesia with sevoflurane [28].

Phantom pain has also been found to be similar when either PCA with fentanyl or an epidural infusion with bupivacaine was started 48 hours preoperatively and continued for 48 hours postoperatively [22].

Thus, good pain control with opioids is important for CPSP prevention, despite their known hyperalgesia risk.

\section{(9) Other pharmacological agents}

Limited studies are available for other drugs, including memantine, dextromethorphan, mexiletine, and nitrous oxide, with variable effects shown on CPSP [42]. Based on the available data, the use of these drugs for the prevention of CPSP cannot be recommended.

\section{5) Psychological intervention}

The association of psychological factors with chronic pain has been well documented. Hinrichs-Rocker did a systematic review on the psychological predictors and correlates for CPSP, and found that depression, psychological vulnerability, stress and late return to work showed a probable correlation with CPSP [47]. Pain catastrophizing is sometimes found to be related to decreased CPSP, which can be due to early medical help being sought [48]. Patients having negative beliefs about opioids have a higher CPSP risk [32].

Adequate preoperative counselling regarding the surgery and expected outcomes can alleviate stress and help prevent CPSP. Identifying psychologically vulnerable patients and early intervention pre- as well as post-operatively may help prevent the development of chronic pain 
in these patients [32].

\section{Management of CPSP}

The management of CPSP depends on the proper identification of the etiology and type of pain via a thorough history-taking and physical examination. Pain existing from the preoperative period, postoperative complications (notable among these are infections), or the recurrence of the primary disease should be ruled out before labeling it as CPSP. More than a half of CPSP patients have neuropathic pain, the remainder having nociceptive (somatic or visceral) pain. A patient may have different components of pain, and these must be identified for effective management.

During the preoperative and early postoperative period, it is very important to provide patient education and counselling about the chances of developing CPSP. Similarly, should chronic pain develop, patients must be counselled about their prognosis, the management plan, and their rehabilitation. Patients should also be counseled about their self-management strategies and their return to normal functioning.

\section{1) Pharmacotherapy}

RCTs of drugs for the management of CPSP are limited, and most of the recommendations have been extrapolated from data for other types of chronic pain, especially neuropathic pain. Similar to other neuropathic pain conditions, anticonvulsants (gabapentin and pregabalin), tricyclic antidepressants (amitriptyline and nortriptyline), serotonin-norepinephrine reuptake inhibitors (duloxetine and venlafaxine), topical lidocaine or topical capsaicin form the first line of treatment for most patients (Table 2).

Paracetamol, NSAIDs, and weak opioids (tramadol and codeine) can be used according to symptom severity, but strong opioids should be used with great caution, weighing the risks and benefits. Other drugs that may be helpful are ketamine, muscle relaxants, clonidine and intravenous lidocaine infusion.

Some studies have found low-concentration capsaicin to be useful for post-mastectomy pain [49]. In contrast, a recent Cochrane review of low concentration $(<1 \%)$ capsaicin cream was not found useful for neuropathic pain [50]; a high concentration was also not useful for persis- tent pain following inguinal herniorrhaphy, though it was useful for postherpetic neuralgia, painful diabetic neuropathy and HIV neuropathy [51]. The number of studies was too limited to form any recommendations.

A 5\% lidocaine patch was found effective for neuropathic pain associated with allodynia following cancer surgery [52]. A conclusion from a meeting of 44 pain specialists from 17 countries, and based on a retrospective analysis of case reports, concluded that CPSP associated with localized, superficial pain and allodynia showed a positive response to $5 \%$ lidocaine plaster [53]. An observational study of patients with posttraumatic and postsurgical localized neuropathic pain also showed a significant reduction in pain and a decrease in painful areas following treatment with lidocaine-medicated plaster [54,55]. A randomized, double-blind, placebo-controlled, cross-over trial among 21 male patient having unilateral severe persistent inguinal pain following herniorrhaphy, showed no significant improvement with a 14 -day application of a $5 \%$ lidocaine patch [56].

A nitroglycerine transdermal patch has been found useful for chronic post-thoracotomy pain [57]. A topical $5 \%$ amitriptyline cream has also been tried, but it was not found to be effective compared with $5 \%$ lidocaine cream or a placebo [58]. A pilot study of topical $1 \%$ amitriptyline, $0.5 \%$ ketamine or their combination for the treatment of neuropathic pain, including CPSP, found the combination cream to be effective after 7 days' application, whereas they were ineffective when applied individually [59]. The subsequent open-label, prospective study with a $2 \%$ amitriptyline/1\% ketamine combination cream applied for 6-12 months showed significant pain relief, with long-term patient satisfaction and minimal side effects [60].

\section{2) Pain interventions}

For patients who do not improve with pharmacotherapy, various interventions have been tried, ranging from nerve blocks to nerve ablation and neuromodulation (Table 2).

Nerve blocks, neuraxial blocks and sympathectomies have been tried. Successful treatment of sternotomy-induced neuralgia has been reported, using repeated bupivacaine blocks, phenol blocks or alcohol blocks [49]. Pain relief was seen with epidural injections for lumbar or cervical post-surgery syndrome [61], but no significant difference was seen when caudal or cervical epidural local anesthetic 


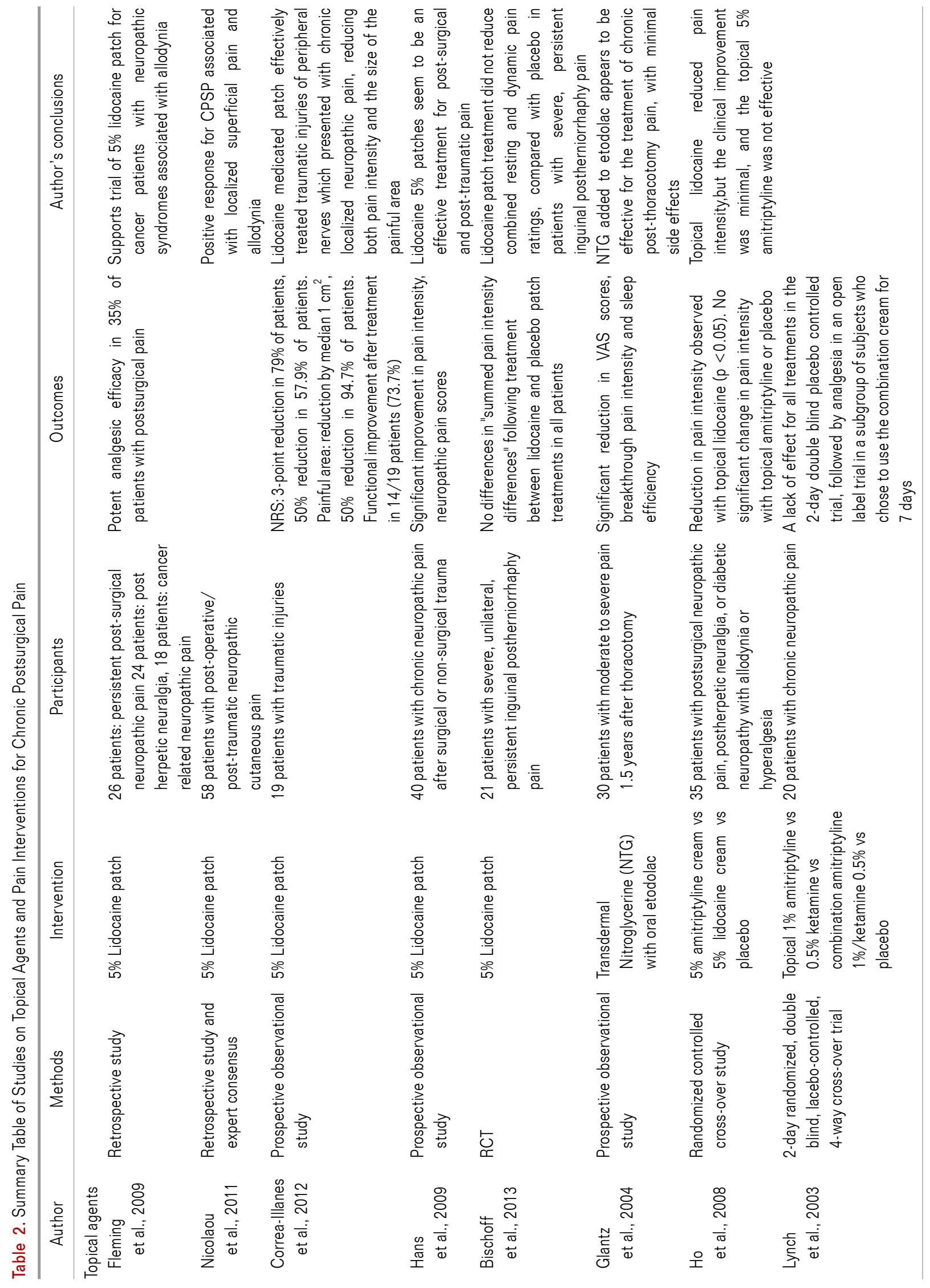




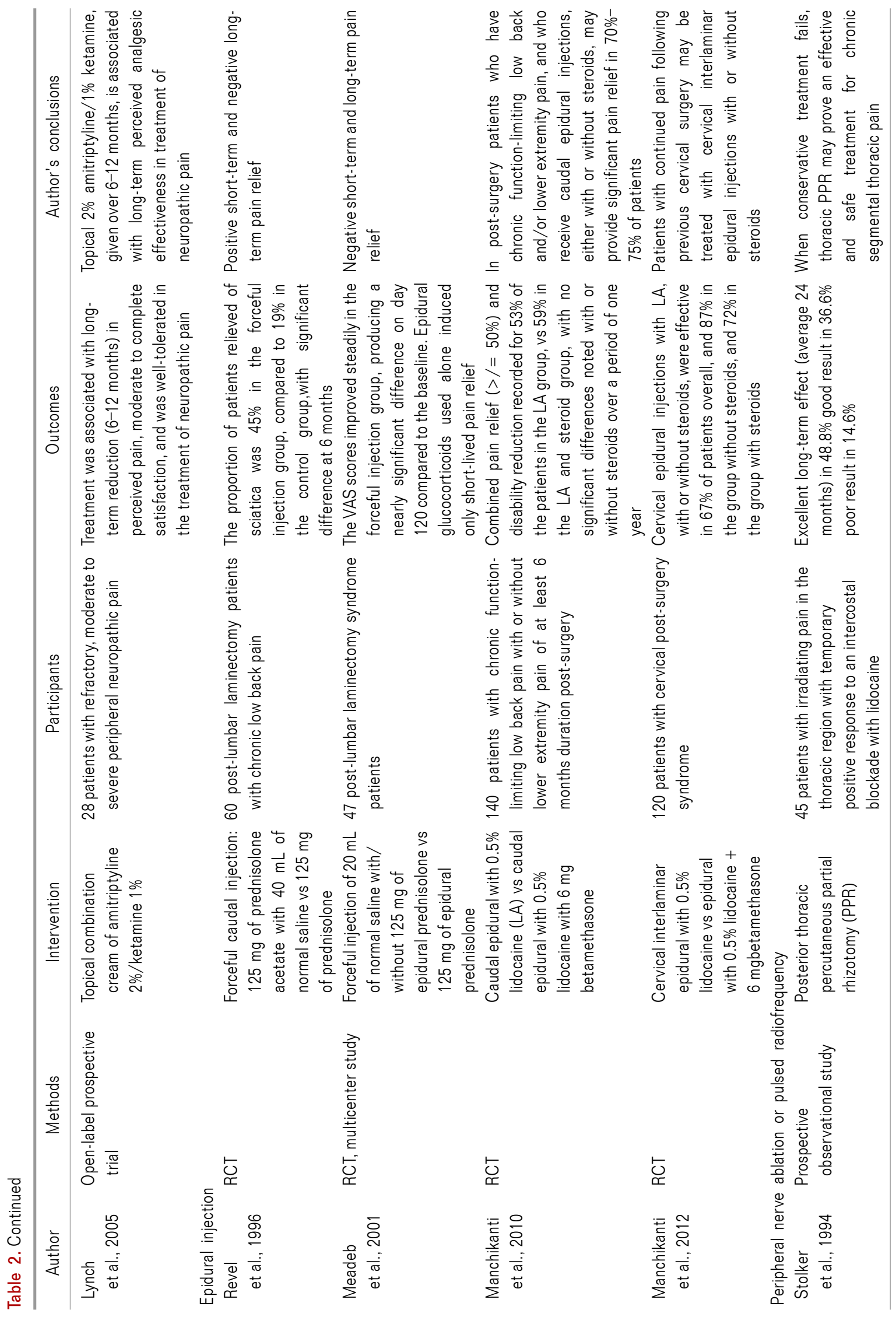




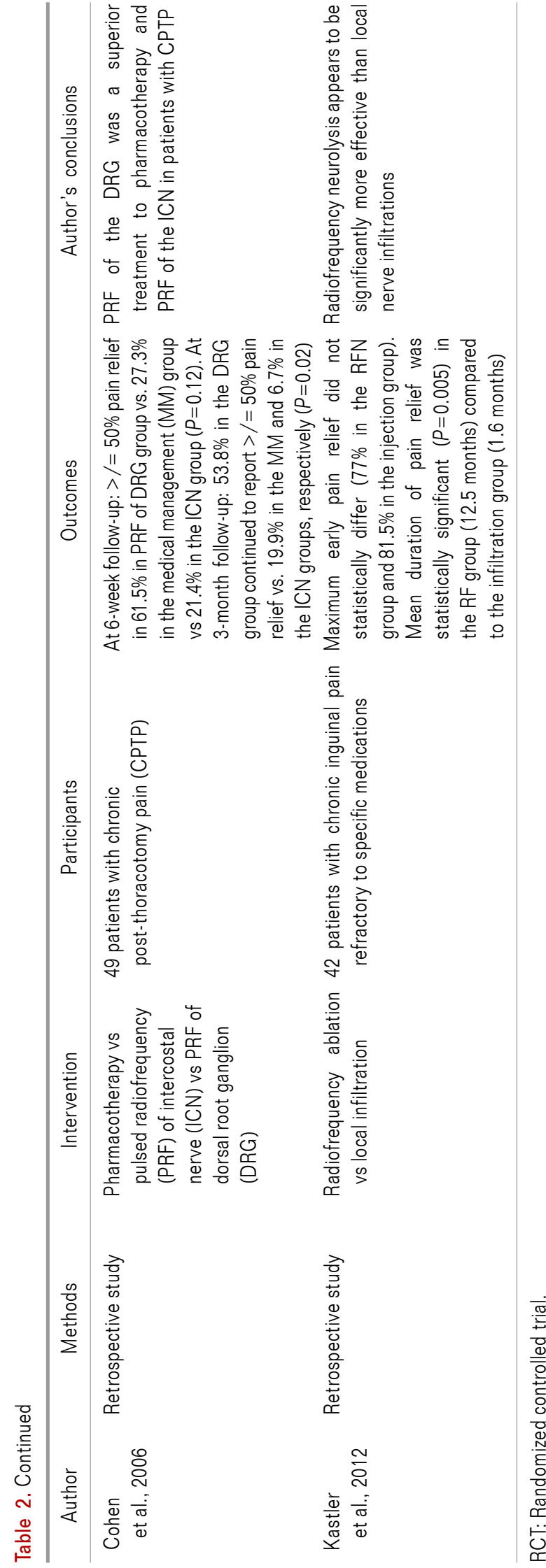

injections alone were used, compared with combined epidural steroid and local anesthetic injections $[62,63]$.

Entrapment of the superficial nerves of the abdominal wall, or trauma to nerves during surgery, can be a source of chronic abdominal wall pain following any abdominal surgery. The injection of local anesthetic agents, with or without steroids, in the transverse abdominis plane, rectus sheath or tender point can produce pain relief in such $\mathrm{pa}^{-}$ tients [64-66]. An axillary brachial plexus block with patient-controlled analgesia was found to be useful for the treatment of complex regional pain syndrome I, developed after surgical release in case of carpel tunnel syndrome [67].

Botulinum toxin injections in the painful areas of chronic post-thoracotomy pain have been reported to provide significant pain relief for patients unresponsive to oral therapy [68]. Positive results have also been seen with botox injections in the area of abdominal wall pain following ventral hernia repair, and for trigeminal neuropathic pain following dental implants $[69,70]$.

Phenol injections or radiofrequency ablation of stump neuroma and dorsal root ganglia have been found useful for stump and phantom pain [71,72]. If other options fail, lesioning the dorsal root entry zone (DREZ) and motor cord stimulation have been found useful [73]. Radiofrequency percutaneous partial rhizotomy has been found to be useful in the management of chronic thoracic segmental pain, including post-thoracotomy and post-mastectomy pain [74]. A retrospective study comparing the effects of pulsed radiofrequency $(\mathrm{PRF})$ of the dorsal root ganglia (DRG) with that of the intercostal nerve (ICN) or medical management found the PRF of DRG to be superior to PRF of the ICN or medical management, in terms of success in pain relief and the duration of pain relief [75]. Radiofrequency ablation of the DRG or the DREZ has been used to successfully treat chronic ilioinguinal pain following inguinal hernia repair, and chronic post-thoracotomy pain [76]. Pulsed radiofrequency treatments to the ilioinguinal and genitofemoral nerves and nerve roots have resulted in complete relief lasting up to 6 months [77] longer than steroid injections [78]. Transcutaneous electrical nerve stimulation and mirror therapy can provide benefits in patients with phantom limb syndrome [79].

Recently, spinal cord stimulation has provided promising results and is commonly used for phantom pain [73]. It has been used for the management of chronic 
post-thoracotomy pain, but the evidence is presently limited to case studies [80]. Its use has also been found effective for the management of neuropathic arm or leg pain following cervical or spinal surgeries, and in complex regional pain syndrome type 1 [81].

\section{3) Surgical management}

For patients with post-mastectomy pain syndrome, surgical resection of the neuroma and allowing the cut-ending of the nerve to retract deep into the intercostal muscles has been found to be helpful [82]. Since a neuroma can reform, relocation of the nerve to a protected site and helping regrowth via a nerve graft can be a better option
[19]. Excision of a painful intercostal neuroma and implantation of the proximal end of the nerve into the latissimus dorsi muscle has been found to be effective for neuromas developed following thoracic and upper abdominal surgeries [83].

An autologous fat graft to the dermo-hypodermal junction at the painful scar area has been shown to be effective [84]. A scar excision can also help relieve pain following surgery. In the case of patients with chronic neuropathic pain following an inguinal herniorrhaphy who are not relieved by conservative measures, some pain relief can be provided by revision surgery; a triple neurectomy of the ilioinguinal nerve, iliohypogastric nerve and genitofemoral nerve; or removal of the fixation material and the

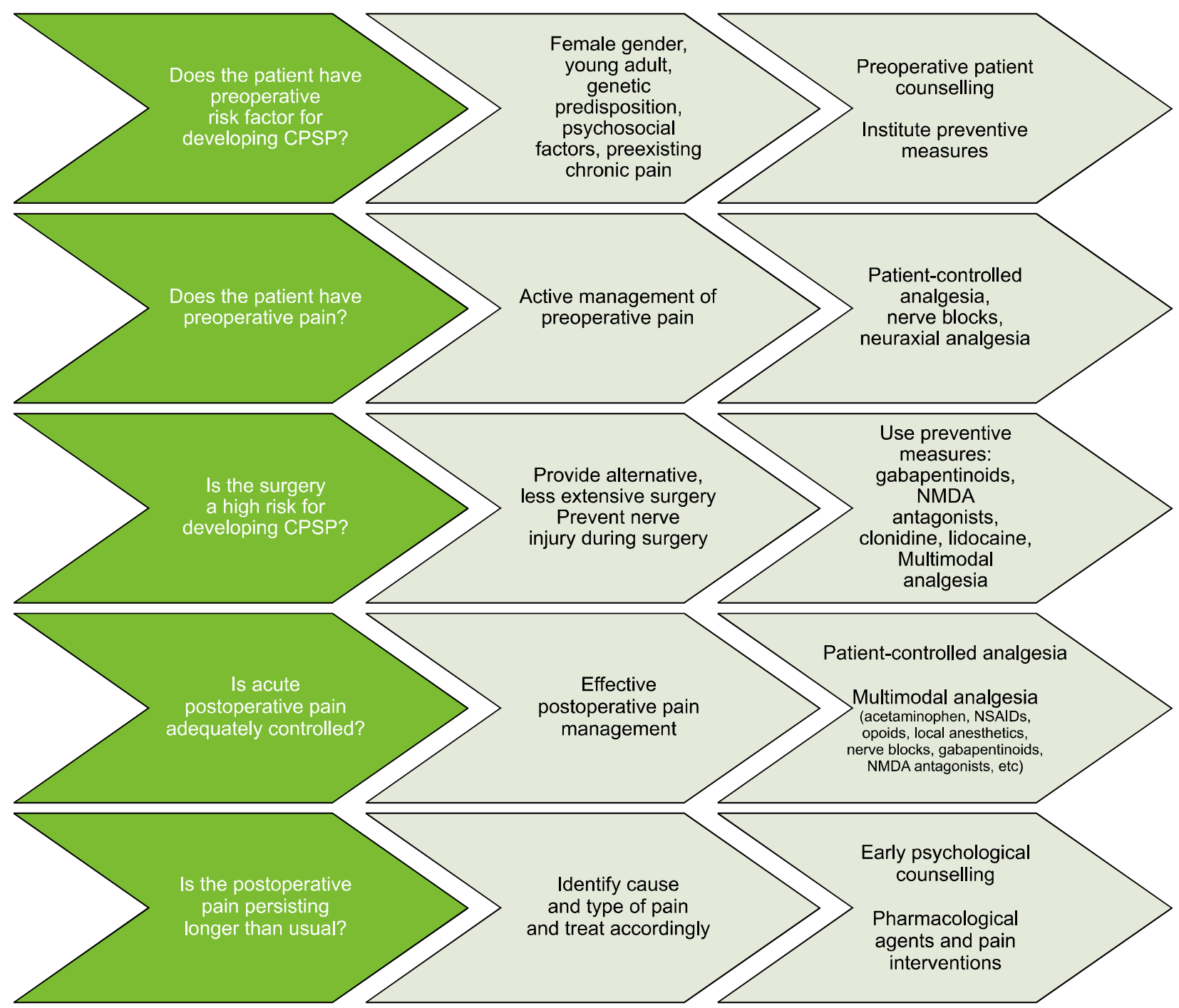

Fig. 1. Step-by-step approach to the prevention of chronic postsurgical pain. 
mesh [85].

Though surgery is an option for pain management in CPSP when other options have failed, we must consider the possibility of the recurrence of CPSP following surgery. Preventive measures, including effective perioperative pain management and counselling, should be instituted on time.

\section{4) Lifestyle modification}

Physical therapies, including massage, physiotherapy and acupuncture, have been tried in the management of CPSP. These modalities can reduce pain, but only temporarily. Lifestyle modifications in the form of rest and activity limitation are not advised as these can lead to further complications, especially poor functional outcomes.

\section{5) Psychological interventions}

Operant conditioning and cognitive behavioral therapy (CBT) have been found to be useful for the management of chronic pain. In operant conditioning, the clinician emphasizes the modification of responses to maladaptive behaviors, and the modification of behaviors that consist of overt expressions of pain, distress and suffering in response to chronic pain. By comparison, CBT focuses on improving physical and emotional functioning despite the pain, rather than attempting to eliminate the pain. It provides positive reinforcement to wellness behavior, physical fitness and cognitive reframing so that the patients can become desensitized to the persistent pain and can function better. It usually combines stress management, problem solving, goal setting, relaxation, and the pacing of activities [86,87].

In a randomized study comparing the effectiveness of lumbar fusion with posterior transpedicular screw fixation, and cognitive intervention and exercises among patients with CPSP after previous surgery for disc herniation, the surgery and the combination of cognitive intervention and exercise showed similar levels of effectiveness in managing the pain [88]. Aggressive exercise with CBT has been found to be useful for various back pain conditions, including those following surgery [89].

\section{CONCLUSIONS}

CPSP is a common but overlooked complication of surgery which can cause functional limitation and psychological distress to patients. Though we are still unable to completely prevent this problem, with a proper knowledge of the condition, we can easily identify the risk factors in a patient undergoing surgery and institute appropriate preventive measures.

These range from modification of the surgical, anesthetic and analgesic techniques to psychological counselling. Any event of CPSP should be identified in a timely manner, and proper management-consisting of pharmacotherapy, appropriate pain interventions, surgery and/or psychological managements by a multidisciplinary team-can improve the pain as well as the physical and social functionality of the patient (Fig. 1).

\section{ACKNOWLEDGEMENTS}

The authors thank Mr David Park for the English editing of the manuscript, and Miss Sunsanee Mali-ong, research assistant, for her administrative support.

\section{CONFLICTS OF INTEREST}

The authors declare that there is no conflicts of interest and no source of funding.

\section{REFERENCES}

1. Macrae WA, Davies HT. Chronic postsurgical pain. In: Epidemiology of pain. Edited by Crombie $\mathbb{K}$, Linton S, Croft P, Von Korff M, LeResche L. Seattle, WA, IASP Press. 1999, pp 125-42.

2. Macrae WA. Chronic pain after surgery. Br J Anaesth 2001; 87: 88-98.

3. Werner MU, Kongsgaard UE. I. Defining persistent postsurgical pain: is an update required? Br J Anaesth 2014; 113: $1-4$

4. Fletcher D, Stamer UM, Pogatzki-Zahn E, Zaslansky R, Tanase NV, Perruchoud C, et al. Chronic postsurgical pain in Europe: an observational study. Eur J Anaesthesiol 2015; 32: 725-34.

5. Schug SA, Pogatzki-Zahn EM. Chronic pain after surgery or injury. In: Pain: clinical updates. Washington, D.C., International Association for the Study of Pain. 2011, p 19.

6. Saxena AK, Chilkoti GT, Chopra AK, Banerjee BD, Sharma T. Chronic persistent post-surgical pain following staging laparotomy for carcinoma of ovary and its relationship to signal transduction genes. Korean J Pain 2016; 29: 239-48. 
7. Bruce J, Quinlan J. Chronic post surgical pain. Rev Pain 2011; 5: 23-9.

8. Kehlet $H$, Jensen TS, Woolf CJ. Persistent postsurgical pain: risk factors and prevention. Lancet 2006; 367: 1618-25.

9. Alfieri S, Rotondi F, Di Giorgio A, Fumagalli U, Salzano A, Di Miceli D, et al. Influence of preservation versus division of ilioinguinal, iliohypogastric, and genital nerves during open mesh herniorrhaphy: prospective multicentric study of chronic pain. Ann Surg 2006; 243: 553-8.

10. McCormack K, Scott NW, Go PM, Ross S, Grant AM; EU Hernia Trialists Collaboration. Laparoscopic techniques versus open techniques for inguinal hernia repair. Cochrane Database Syst Rev 2003: CD001785.

11. Karthikesalingam A, Markar SR, Holt PJ, Praseedom RK. Meta-analysis of randomized controlled trials comparing laparoscopic with open mesh repair of recurrent inguinal hernia. Br J Surg 2010; 97: 4-11.

12. Bignell M, Partridge G, Mahon D, Rhodes M. Prospective randomized trial of laparoscopic (transabdominal preperitoneal-TAPP) versus open (mesh) repair for bilateral and recurrent inguinal hernia: incidence of chronic groin pain and impact on quality of life: results of 10 year follow-up. Hernia 2012; 16: 635-40.

13. Recker DC, Perry PM. Postsurgical pain syndromes: Chronic pain after hysterectomy and cesarean section. Tech Reg Anesth Pain Manage 2011; 15: 133-9.

14. Brandsborg B. Pain following hysterectomy: epidemiological and clinical aspects. Dan Med J 2012; 59: B4374.

15. Gottschalk A, Cohen SP, Yang S, Ochroch EA. Preventing and treating pain after thoracic surgery. Anesthesiology 2006; 104: 594-600.

16. Vilardo L, Shah M. Chronic pain after hip and knee replacement. Tech Reg Anesth Pain Manage 2011; 15: 110-5.

17. Huang AP, Sakata RK. Pain after sternotomy - review. Braz J Anesthesiol 2016; 66: 395-401.

18. Kraychete DC, Sakata RK, Lannes LO, Bandeira ID, Sadatsune EJ. Postoperative persistent chronic pain: what do we know about prevention, risk factors, and treatment. Braz J Anesthesiol 2016; 66: 505-12.

19. Jung BF, Ahrendt GM, Oaklander AL, Dworkin RH. Neuropathic pain following breast cancer surgery: proposed classification and research update. Pain 2003; 104: 1-13.

20. Clarke H, Woodhouse LJ, Kennedy D, Stratford P, Katz J. Strategies aimed at preventing chronic post-surgical pain: comprehensive perioperative pain management after total joint replacement surgery. Physiother Can 2011; 63: 289304.

21. Reddi D. Preventing chronic postoperative pain. Anaesthesia 2016; 71 Suppl 1: 64-71.

22. Karanikolas M, Aretha D, Tsolakis I, Monantera G, Kiekkas P. Papadoulas S, et al. Optimized perioperative analgesia reduces chronic phantom limb pain intensity, prevalence, and frequency: a prospective, randomized, clinical trial. Anesthesiology 2011; 114: 1144-54.

23. Buvanendran A. Multimodal analgesia for perioperative pain management. In: IARS 2011 review course lectures. Washington, D.C., International Association for the Study of Pain. 2011.

24. Albi-Feldzer A, Mouret-Fourme EE, Hamouda S, Motamed C, Dubois PY, Jouanneau L, et al. A double-blind randomized trial of wound and intercostal space infiltration with ropivacaine during breast cancer surgery: effects on chronic postoperative pain. Anesthesiology 2013; 118: 318-26.

25. Andreae MH, Andreae DA. Regional anaesthesia to prevent chronic pain after surgery: a Cochrane systematic review and meta-analysis. Br J Anaesth 2013; 111: 711-20.

26. Borghi B, D'Addabbo M, White PF, Gallerani P, Toccaceli L, Raffaeli $W$, et al. The use of prolonged peripheral neural blockade after lower extremity amputation: the effect on symptoms associated with phantom limb syndrome. Anesth Analg 2010; 111: 1308-15.

27. Van de Ven TJ, John Hsia HL. Causes and prevention of chronic postsurgical pain. Curr Opin Crit Care 2012; 18: 366-71.

28. Humble SR, Dalton AJ, Li L. A systematic review of therapeutic interventions to reduce acute and chronic postsurgical pain after amputation, thoracotomy or mastectomy. Eur J Pain 2015; 19: 451-65.

29. Clarke H, Bonin RP, Orser BA, Englesakis M, Wijeysundera DN, Katz J. The prevention of chronic postsurgical pain using gabapentin and pregabalin: a combined systematic review and meta-analysis. Anesth Analg 2012; 115: 428-42.

30. Sentürk M, Ozcan PE, Talu GK, Kiyan E, Camci E, Ozyalçin $S$, et al. The effects of three different analgesia techniques on long-term postthoracotomy pain. Anesth Analg 2002; 94: $11-5$.

31. Gupta A, Gandhi K, Viscusi ER. Persistent postsurgical pain after abdominal surgery. Tech Reg Anesth Pain Manage 2011; 15: 140-6.

32. Clarke $H$, Poon M, Weinrib A, Katznelson R, Wentlandt $K$, Katz J. Preventive analgesia and novel strategies for the prevention of chronic post-surgical pain. Drugs 2015; 75: 339-51.

33. Fassoulaki A, Triga A, Melemeni A, Sarantopoulos C. Multimodal analgesia with gabapentin and local anesthetics prevents acute and chronic pain after breast surgery for cancer. Anesth Analg 2005; 101: 1427-32.

34. Mishriky BM, Waldron NH, Habib AS. Impact of pregabalin on acute and persistent postoperative pain: a systematic review and meta-analysis. Br J Anaesth 2015; 114: 10-31.

35. Schmidt PC, Ruchelli G, Mackey SC, Carroll IR. Perioperative gabapentinoids: choice of agent, dose, timing, and effects 
on chronic postsurgical pain. Anesthesiology 2013; 119 : 1215-21.

36. Martinez $V$, Pichard X, Fletcher D. Perioperative pregabalin administration does not prevent chronic postoperative pain: systematic review with a meta-analysis of randomized trials. Pain 2017; 158: 775-83.

37. Amr YM, Yousef AA. Evaluation of efficacy of the perioperative administration of Venlafaxine or gabapentin on acute and chronic postmastectomy pain. Clin J Pain 2010; 26: $381-5$.

38. Wong K, Phelan R, Kalso E, Galvin I, Goldstein D, Raja S, et al. Antidepressant drugs for prevention of acute and chronic postsurgical pain: early evidence and recommended future directions. Anesthesiology 2014; 121 : 591-608.

39. McGreevy K, Bottros MM, Raja SN. Preventing chronic pain following acute pain: risk factors, preventive strategies, and their efficacy. Eur J Pain Suppl 2011; 5: 365-72.

40. McNicol ED, Schumann R, Haroutounian S. A systematic review and meta-analysis of ketamine for the prevention of persistent post-surgical pain. Acta Anaesthesiol Scand 2014; 58: 1199-213.

41. Grigoras A, Lee P, Sattar F, Shorten G. Perioperative intravenous lidocaine decreases the incidence of persistent pain after breast surgery. Clin J Pain 2012; 28: 567-72.

42. Chaparro LE, Smith SA, Moore RA, Wiffen PJ, Gilron I. Pharmacotherapy for the prevention of chronic pain after surgery in adults. Cochrane Database Syst Rev 2013: CD008307.

43. Fransen M, Anderson C, Douglas J, MacMahon S, Neal B, Norton R, et al. Safety and efficacy of routine postoperative ibuprofen for pain and disability related to ectopic bone formation after hip replacement surgery (HIPAID): randomised controlled trial. BMJ 2006; 333: 519.

44. Reuben SS, Ekman EF. The effect of initiating a preventive multimodal analgesic regimen on long-term patient outcomes for outpatient anterior cruciate ligament reconstruction surgery. Anesth Analg 2007; 105: 228-32.

45. Weis F, Kilger E, Roozendaal B, de Quervain DJ, Lamm P, Schmidt $M$, et al. Stress doses of hydrocortisone reduce chronic stress symptoms and improve health-related quality of life in high-risk patients after cardiac surgery: a randomized study. J Thorac Cardiovasc Surg 2006; 131 : 277-82.

46. Nielsen RV, Fomsgaard J, Mathiesen O, Dahl JB. The effect of preoperative dexamethasone on pain 1 year after lumbar disc surgery: a follow-up study. BMC Anesthesiol 2016; 16: 112.

47. Hinrichs-Rocker A, Schulz K, Järvinen I, Lefering R, Simanski C, Neugebauer EA. Psychosocial predictors and correlates for chronic post-surgical pain (CPSP) - a systematic review. Eur J Pain 2009; 13: 719-30.
48. Katz J, Seltzer Z. Transition from acute to chronic postsurgical pain: risk factors and protective factors. Expert Rev Neurother 2009; 9: 723-44.

49. Eisenberg E. Post-surgical neuralgia. Pain 2004; 111: 3-7.

50. Derry S, Moore RA. Topical capsaicin (low concentration) for chronic neuropathic pain in adults. Cochrane Database Syst Rev 2012: CD010111.

51. Derry S, Rice AS, Cole P, Tan T, Moore RA. Topical capsaicin (high concentration) for chronic neuropathic pain in adults. Cochrane Database Syst Rev 2017: CD007393.

52. Fleming JA, O'Connor BD. Use of lidocaine patches for neuropathic pain in a comprehensive cancer centre. Pain Res Manag 2009; 14: 381-8.

53. Nicolaou A, Nicholson B, Hans G, Brasseur L. Outcome predictors for treatment success with 5\% lidocaine medicated plaster in low back pain with neuropathic components and neuropathic pain after surgical and nonsurgical trauma. $J$ Pain Res 2011; 4: 25-38.

54. Correa-Illanes G, Roa R, Piñeros JL, Calderón W. Use of $5 \%$ lidocaine medicated plaster to treat localized neuropathic pain secondary to traumatic injury of peripheral nerves. Local Reg Anesth 2012; 5: 47-53.

55. Hans G, Joukes E, Verhulst J, Vercauteren M. Management of neuropathic pain after surgical and non-surgical trauma with lidocaine 5\% patches: study of 40 consecutive cases. Curr Med Res Opin 2009; 25: 2737-43.

56. Bischoff JM, Petersen M, Uçeyler N, Sommer C, Kehlet H, Werner MU. Lidocaine patch (5\%) in treatment of persistent inguinal postherniorrhaphy pain: a randomized, doubleblind, placebo-controlled, crossover trial. Anesthesiology 2013; 119: 1444-52.

57. Glantz L, Godovic G, Lekar M, Kramer M, Eidelman LA. Efficacy of transdermal nitroglycerin combined with etodolac for the treatment of chronic post-thoracotomy pain: an open-label prospective clinical trial. J Pain Symptom Manage 2004; 27: 277-81.

58. Ho KY, Huh BK, White WD, Yeh CC, Miller EJ. Topical amitriptyline versus lidocaine in the treatment of neuropathic pain. Clin J Pain 2008; 24: 51-5.

59. Lynch ME, Clark AJ, Sawynok J. A pilot study examining topical amitriptyline, ketamine, and a combination of both in the treatment of neuropathic pain. Clin J Pain 2003; 19: 323-8.

60. Lynch ME, Clark AJ, Sawynok J, Sullivan MJ. Topical amitriptyline and ketamine in neuropathic pain syndromes: an open-label study. J Pain 2005; 6: 644-9.

61. Abdi S, Datta S, Trescot AM, Schultz DM, Adlaka R, Atluri SL, et al. Epidural steroids in the management of chronic spinal pain: a systematic review. Pain Physician 2007; 10: 185-212.

62. Manchikanti L, Singh V, Cash KA, Pampati V, Datta S. Management of pain of post lumbar surgery syndrome: 
one-year results of a randomized, double-blind, active controlled trial of fluoroscopic caudal epidural injections. Pain Physician 2010; 13: 509-21.

63. Manchikanti L, Malla Y, Cash KA, McManus CD, Pampati V. Fluoroscopic cervical interlaminar epidural injections in managing chronic pain of cervical postsurgery syndrome: preliminary results of a randomized, double-blind, active control trial. Pain Physician 2012; 15: 13-25.

64. Sharpstone D, Colin-Jones DG. Chronic, non-visceral abdominal pain. Gut 1994; 35: 833-6.

65. Guirguis MN, Abd-Elsayed AA, Girgis G, Soliman LM. Ultrasound-guided transversus abdominis plane catheter for chronic abdominal pain. Pain Pract 2013; 13: 235-8.

66. Lindsetmo RO, Stulberg J. Chronic abdominal wall pain--a diagnostic challenge for the surgeon. Am J Surg 2009; 198 : 129-34.

67. Wang LK, Chen HP, Chang PJ, Kang FC, Tsai YC. Axillary brachial plexus block with patient controlled analgesia for complex regional pain syndrome type I: a case report. Reg Anesth Pain Med 2001; 26: 68-71.

68. Fabregat G, Asensio-Samper JM, Palmisani S, VillanuevaPérez VL, De Andrés J. Subcutaneous botulinum toxin for chronic post-thoracotomy pain. Pain Pract 2013; 13: 231-4.

69. Smoot D, Zielinski M, Jenkins D, Schiller H. Botox A injection for pain after laparoscopic ventral hernia: a case report. Pain Med 2011; 12: 1121-3.

70. Argoff CE. A focused review on the use of botulinum toxins for neuropathic pain. Clin J Pain 2002; 18: S177-81.

71. Ganapathy S, Brookes J. Chronic postsurgical pain after nonarthroplasty orthopedic surgery. Tech Reg Anesth Pain Manage 2011; 15: 116-23.

72. Ramanavarapu V, Simopoulos TT. Pulsed radiofrequency of lumbar dorsal root ganglia for chronic post-amputation stump pain. Pain Physician 2008; 11: 561-6.

73. Manchikanti $L$, Singh $V$. Managing phantom pain. Pain Physician 2004; 7: 365-75.

74. Stolker RJ, Vervest AC, Groen GJ. The treatment of chronic thoracic segmental pain by radiofrequency percutaneous partial rhizotomy. J Neurosurg 1994; 80: 986-92.

75. Cohen SP, Sireci A, Wu CL, Larkin TM, Williams KA, Hurley RW. Pulsed radiofrequency of the dorsal root ganglia is superior to pharmacotherapy or pulsed radiofrequency of the intercostal nerves in the treatment of chronic postsurgical thoracic pain. Pain Physician 2006; 9: 227-35.
76. Byrd D, Mackey S. Pulsed radiofrequency for chronic pain. Curr Pain Headache Rep 2008; 12: 37-41.

77. Rea W, Kapur S, Mutagi H. Radiofrequency therapies in chronic pain. Contin Educ Anaesth Crit Care Pain 2011; 11: 35-8.

78. Kastler A, Aubry S, Piccand V, Hadjidekov G, Tiberghien F, Kastler B. Radiofrequency neurolysis versus local nerve infiltration in 42 patients with refractory chronic inguinal neuralgia. Pain Physician 2012; 15: 237-44.

79. Subedi B, Grossberg GT. Phantom limb pain: mechanisms and treatment approaches. Pain Res Treat 2011; 2011: 864605

80. Graybill J, Conermann T, Kabazie AJ, Chandy S. Spinal cord stimulation for treatment of pain in a patient with post thoracotomy pain syndrome. Pain Physician 2011; 14: 441-5.

81. Shipton E. Post-surgical neuropathic pain. ANZ J Surg 2008; 78: 548-55.

82. Wong L. Intercostal neuromas: a treatable cause of postoperative breast surgery pain. Ann Plast Surg 2001; 46: 481-4.

83. Williams EH, Williams CG, Rosson GD, Heitmiller RF, Dellon AL. Neurectomy for treatment of intercostal neuralgia. Ann Thorac Surg 2008; 85: 1766-70.

84. Caviggioli F, Maione L, Forcellini D, Klinger F, Klinger M. Autologous fat graft in postmastectomy pain syndrome. Plast Reconstr Surg 2011; 128: 349-52.

85. Hakeem A, Shanmugam V. Current trends in the diagnosis and management of post-herniorraphy chronic groin pain. World J Gastrointest Surg 2011; 3: 73-81.

86. Eccleston $\mathrm{C}$. Role of psychology in pain management. $\mathrm{Br} \mathrm{J}$ Anaesth 2001; 87: 144-52.

87. Turk DC, Audette J, Levy RM, Mackey SC, Stanos S. Assessment and treatment of psychosocial comorbidities in patients with neuropathic pain. Mayo Clin Proc 2010; 85: S42-50.

88. Brox J, Reikerås $\mathrm{O}$, Nygaard $\varnothing, S \varnothing$ rensen $R$, Indahl A, Holm I, et al. Lumbar instrumented fusion compared with cognitive intervention and exercises in patients with chronic back pain after previous surgery for disc herniation: a prospective randomized controlled study. Pain 2006; 122: 145-55.

89. Cohen I, Rainville J. Aggressive exercise as treatment for chronic low back pain. Sports Med 2002; 32: 75-82. 